\title{
AWARENESS OF PHARMACOVIGILANCE AMONG MEDICAL STUDENTS
}

\author{
M. Ananda Babu Naik1, R. Asha Latha², Siva Sankara Murthy ${ }^{3}$ \\ ${ }^{1}$ Assistant Professor, Department of Orthopaedics, Government Medical College, Anantapuram. \\ ${ }^{2}$ Associate Professor, Department of Pharmacology, Sri Venkateswara Medical College, Tirupati. \\ ${ }^{3}$ Assistant Professor, Department of Orthopaedics, Government Medical College, Anantapuram.
}

\begin{tabular}{ll}
\hline & ABSTRACT \\
\hline Have a major impact on public health.
\end{tabular}

Have a major impact on public health.

AIM

To assess the awareness of Pharmacovigilance among third year medical students.

\section{MATERIAL AND METHODS}

This was an observational study. The study was conducted on fifth semester medical students in the Department of Pharmacology, Government Medical College, Anantapur. A questionnaire containing 15 questions with 2-5 options were given to each student and they were asked to mark one best suitable option. We analysed data of 80 students. The results were evaluate d graphically using Microsoft Excel sheet.

\section{RESULTS}

89.93\% of students were aware of all the activities involved in Pharmacovigilance; $48.48 \%$ of the students had an idea that all the health care professionals (i.e. doctors, pharmacists, nurses) are responsible for reporting adverse drug reaction $34.84 \%$ of students had wrong perception that WHO online database for reporting ADRs was Medsafe and 31.8\% thought Vigibase as online database; $48.48 \%$ had the correct understanding that CDSCO is the regulatory body for monitoring ADRs in India; $66.66 \%$ students thought that all the Adverse drug reactions (Mild, moderate, severe) irrespective of their severity have to be reported; $61 \%$ of students thought that ADR reporting is a Professional obligation; 91\% of the students were aware that all the measures (Stop the drug, report ADR and treat the condition) have to be taken when an ADR is suspected. Other factors included like $68 \%$ students knew drugs banned because of ADR. Majority of students wrote Thalidomide and Nimesulide as an example for a drug banned because of ADR.

\section{CONCLUSION}

The current study revealed that medical students had good awareness.

\section{KEYWORDS}

Pharmacovigilance, Adverse Drug Reactions, Medical Students.

HOW TO CITE THIS ARTICLE: Naik MAB, Latha RA, Murthy SS. Awareness of pharmacovigilance among medical students. J. Evolution Med. Dent. Sci. 2016;5(72):5273-5276, DOI: 10.14260/jemds/2016/1195

\section{INTRODUCTION}

Since time immemorial, the use of medicines has been associated with adverse effects. "There are 3 actions of a drug: The one you want, the one you don't want and the one you don't know about" (DJP Barker).[1] So, it is crucial to monitor both the known and the unknown adverse effects of medicines. This is because the recent epidemiological studies have estimated that adverse drug reactions are the fourth to sixth leading causes of death and that they represent $5 \%$ to $10 \%$ of the hospital costs.[2] Therefore, in addition to the obvious morbidity and the mortality which are caused by them, ADRs are also an economic burden on our health care system, as they prolong the hospital stay and increase the cost of the treatment.

Financial or Other, Competing Interest: None.

Submission 07-06-2016, Peer Review 23-08-2016,

Acceptance 31-08-2016, Published 07-09-2016.

Corresponding Author:

Dr. R. Asha Latha

D-No. 13-2-128,

Shirdinagar, Anantapuram.

E-mail: lathasha05@gmail.com

DOI: $10.14260 /$ jemds $/ 2016 / 1195$

(c) $($ ) $\$$
In a country like India with a large population and vast diversity, it is absolutely necessary to introduce a standard pharmacovigilance programme. Pharmacovigilance is by definition, "The science and activities which are related to the detection, assessment, understanding and the prevention of adverse effects or any other drug related problems."[3] India ranks below $1 \%$ in terms of ADR reporting against the world rate of $5 \%{ }^{[4]}$ To overcome this problem, the Ministry of Health and Family Welfare, Govt. of India, has initiated the National Pharmacovigilance Programme. The purpose of this programme is to collate the data, analyse it and to use the inferences to recommend informed regulatory interventions, besides communicating the risks to the health care professionals and the public. This programme is coordinated by the National Pharmacovigilance Centre at the Central Drugs Standard Control Organization (CDSCO) in New Delhi. The National Centre is operating under the supervision of the National Pharmacovigilance Advisory Committee to recommend procedures and guidelines for regulatory interventions. This committee oversees the performance of two zonal, five regional and twenty six peripheral pharmacovigilance centres. The entire network works in coordination to improve the ADR reporting in our country.[5] 
A majority of India's population prefers government hospitals when they are in need of health care facilities. So, these hospitals can be a good source for generating an ADR database. However, the Herculean task is to foster a culture of reporting among the clinicians, especially among the junior doctors as they are more closely associated with the patient care. The present low level of ADR reporting is mostly due to a lack of awareness and training and time constraints.[6]

The manner in which a doctor takes the clinical history of a patient can be improved if he has a sound knowledge of the drug safety issues with an emphasis on the patient's medication history. It also helps him in understanding the action of the drug better. It thus decreases the irrational use of medicines, adverse drug-drug interactions and inappropriate polypharmacy.[7]

Few studies had been carried out in different countries to assess the knowledge of pharmacovigilance among the medical students and practitioners. In the U.K., $57 \%$ of the medical schools assessed the students' knowledge on the yellow card scheme.[8] In France, a survey which was conducted among medical residents showed that a majority lacked knowledge on pharmacovigilance. ${ }^{[9]} \mathrm{A}$ study which was conducted in Nigeria revealed an inadequate knowledge on pharmacovigilance among resident doctors. ${ }^{[10]}$ A study which was designed to investigate the awareness of pharmacovigilance among the health care professionals in Jiangsu, China, showed that significant differences existed in the awareness of pharmacovigilance across regions, hospital classes and professions.[11] A study which was conducted at a Nepalese hospital also showed low KAP scores and it suggested the need for educational and managerial interventions.[12]

In India few studies were carried out, which mainly emphasised on the actual process of the ADR reporting. A study which was conducted at 3 different private hospitals in Mysore recommended that several studies of a similar kind, especially in the community setup needed to be conducted to know the attitudes of other health care professionals towards the ADR reporting.

\section{MATERIALS AND METHODS}

This was an observational, cross-sectional study based on the questionnaire. The study was conducted on 2 nd year (Fifth term) medical students in the Department of Pharmacology of Government Medical College, Anantapur. Prior permission was obtained from the Institutional Ethics Committee. A questionnaire containing 15 questions with 2-5 options were given to the student and they were asked to mark one best suitable option. (Annexure-1) instructed not to reveal their identity in the questionnaire. Twenty minutes was the time allotted to answer the questionnaire. The questionnaire was based on previous studies undertaken on Pharmacovigilance and it was suitably modified for students. The completed questionnaire was collected and data was analysed. Totally 70 students participated in the study, out of which 4 questionnaires were incomplete and eliminated while evaluating results. So, we analysed data of 66 participants. The results were evaluated graphically using Microsoft Excel.

\section{RESULTS}

Majority of the students had correct understanding regarding Pharmacovigilance and its role in identifying the safety of drugs; $89.93 \%$ of students were aware of all the activities involved in Pharmacovigilance. [Figure 1] $48.48 \%$ of the students had an idea that health care professionals (i.e. doctors, pharmacists, nurses) are responsible for reporting ADR. (Figure 2) $34.84 \%$ of students had wrong perception that WHO online database for reporting ADRs was Medsafe and $31.81 \%$ thought Vigibase as WHO online database. (Figure 3) $48.48 \%$ had the correct understanding that CDSCO is the regulatory body for monitoring ADRs in India. (Figure 4) $66.66 \%$ students thought that all the ADRs (mild, moderate and of their severity have to be reported. (Figure 5) 61\% of students thought that ADR reporting is a Professional obligation. (Figure 6) students were aware that all the measures (Stop the drug, report ADR, treat the cause have to be taken when an ADR is suspected). (Figure 7) Other findings include - $68 \%$ students knew drugs banned because of ADR. Majority of students wrote Thalidomide as an example for a drug banned because of ADR.

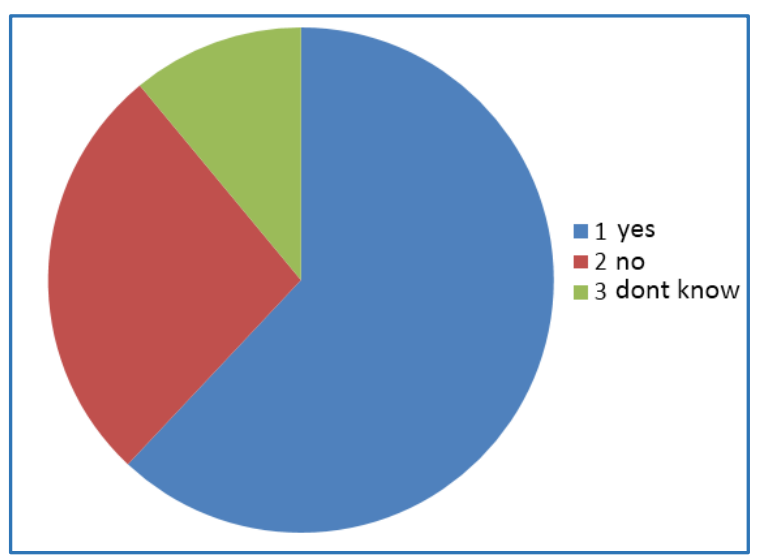

Fig. 1: In Pharmacovigilance

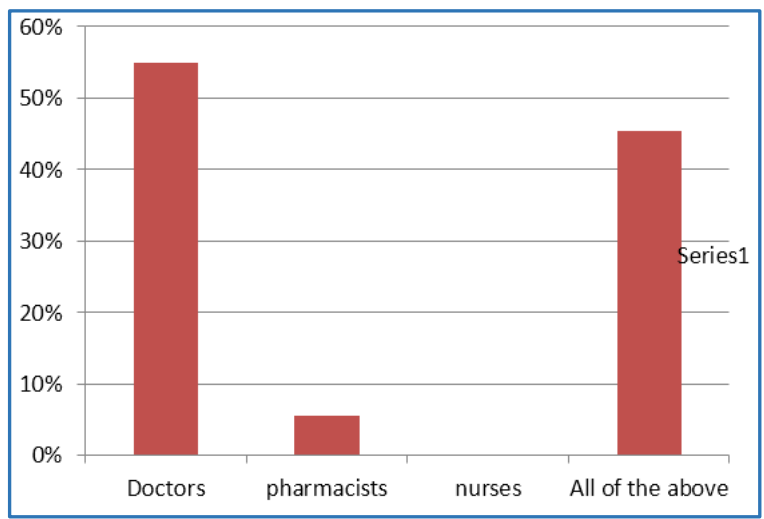

Fig. 2: Health Care Professionals Responsible for Reporting Adverse Drug Reactions

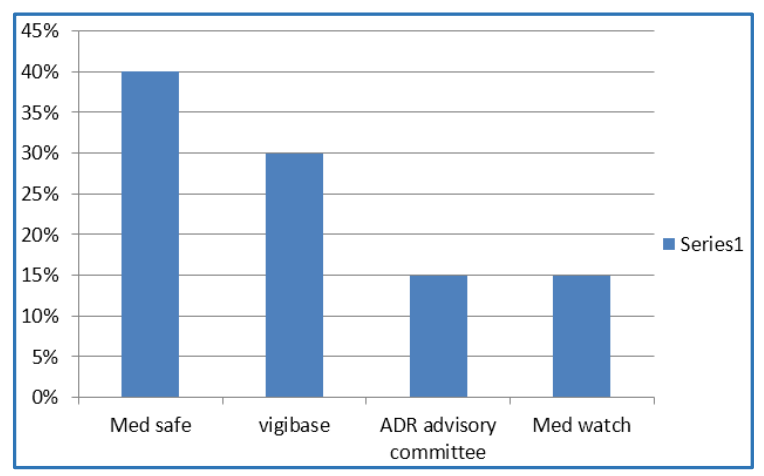

Fig. 3: WHO Online Database for Reporting Adverse Drug Reactions 


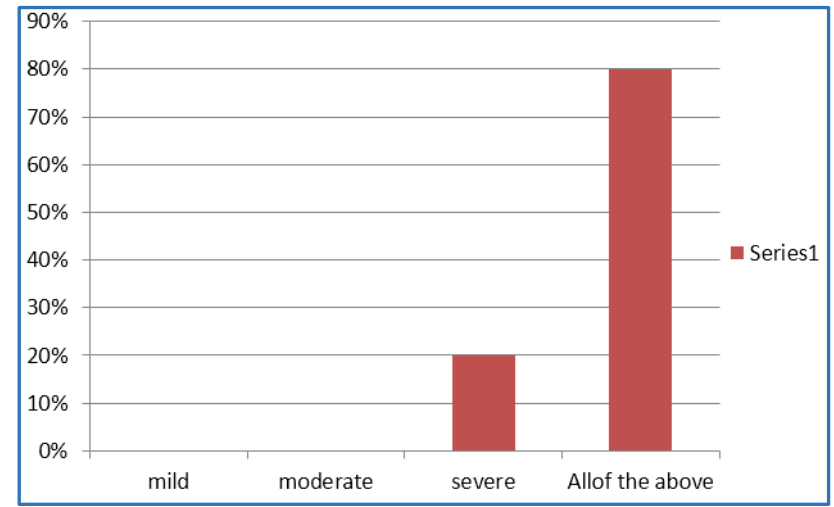

Fig. 4: Types of ADRs to be Monitored

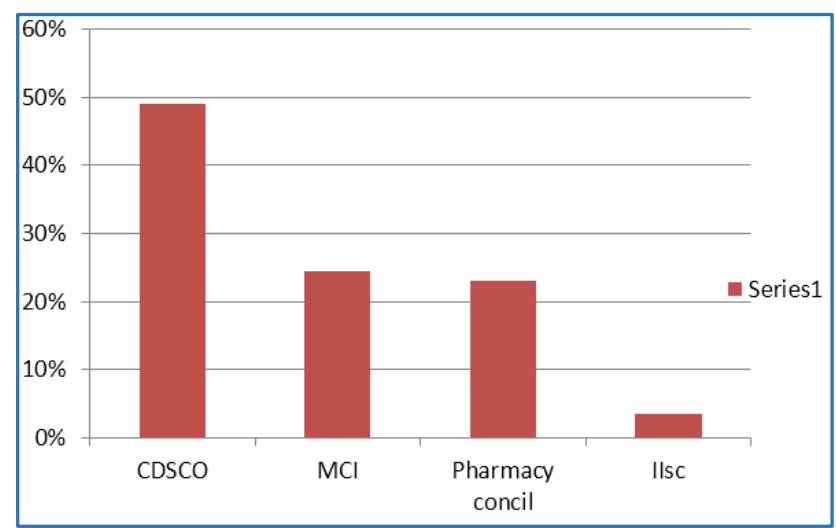

Fig. 5: Regulatory Body for Monitoring Adverse Drug Reactions

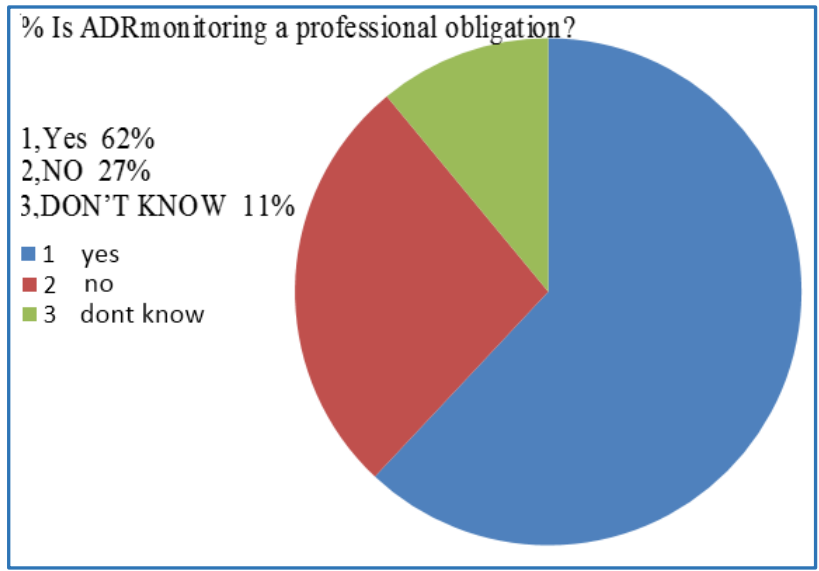

Fig. 6

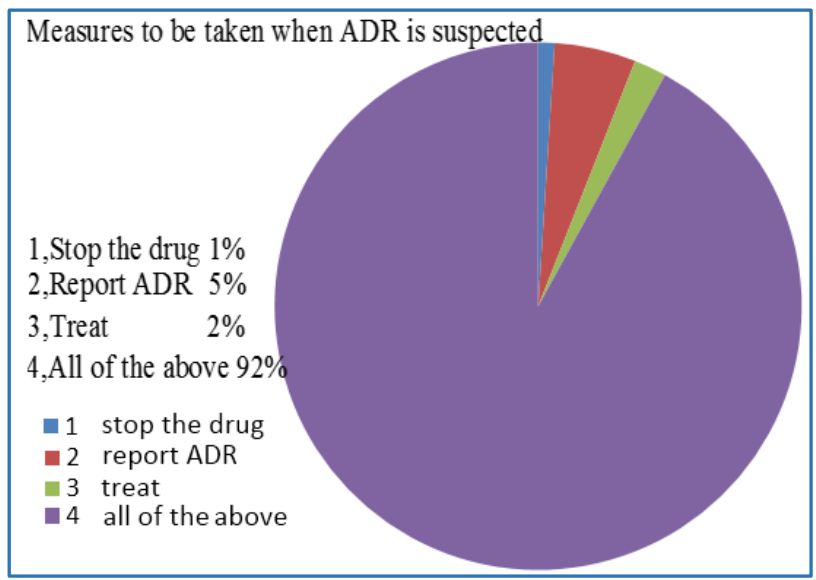

Fig. 7

\section{DISCUSSION}

Adverse effects due to medicines are common cause of mortality and morbidity. ADRs have a major impact on public health by imposing a considerable economic burden on the society. It is estimated that only $6-10 \%$ of all ADRs are reported and underreporting of ADR is a major problem. The aim of Pharmacovigilance Programme of India (PvPI) is to ensure rational therapy by encouraging the adverse drug reaction monitoring. In our present study, $92 \%$ of the students were aware of activities involved in Pharmacovigilance compared to $26 \%$ in a study done by Rehan et al[12] and $94 \%$ reported by Deepak et al[13] In our study, $49 \%$ of participants were aware of the regulatory body responsible for monitoring ADRs, which was low when compared to $84 \%$ reported by Radhakrishnan et al[14] and 79\% reported by Deepak P et al[13] Regarding reporting of ADRs based on severity, in our study $80 \%$ of students had an opinion that all ADRs should be reported irrespective of the severity, whereas in a study done by Rehan et al[12] around $65 \%$ students had the similar opinion and $84 \%$ in a study by Deepak et al. In our study, $62 \%$ students thought that ADR reporting is a professional obligation. In another study by Deepak et al[13] only $47 \%$ of students thought that ADR reporting is a professional obligation. The reason for this difference could not be ascertained. In our study, 92\% of students were aware of the measures that are to be taken when an ADR is suspected and similar was the result in a study by Deepak et al[13] who reported $93 \%$ of the students had awareness about measures to be taken when an adverse drug reaction is suspected. The overall results of this study was encouraging considering the fact that most of the students were aware of the Pharmacovigilance, its activities, measures to be taken when ADR is suspected, type of ADR to be reported, regulatory body monitoring ADR's, the healthcare professionals responsible for reporting ADRs. This encouraging results may be because, have included Pharmacovigilance problem based learning as a part of Practical curriculum and it reflects the students' understanding on the subject. But still there were some grey areas considering that most of students got it wrong when responding to the WHO online database for reporting ADRs.

\section{CONCLUSION}

The current study revealed that medical students had good awareness about Pharmacovigilance and ADR reporting. Better understanding of the subject on Pharmacovigilance in these undergraduates would help them as future doctors in improving the quality of health care as well as safety of the patients.

\section{REFERENCES}

1. The World Health Organization. Safety of medicines-a guide to detecting and reporting adverse drug reactions. Geneva 2002.

2. Oshikoya KA, Awobusuyi JO. Perceptions of doctors to adverse drug reaction reporting in a teaching hospital in Lagos, Nigeria. BMC Clin Pharmacol 2009;9:14.

3. Ayani I, Aguirre C, Gutierrez G, et al. A cost analysis of suspected adverse drug reactions in a hospital emergency ward. Pharmacoepidemiol Drug Saf 1999;8(7):529-34.

4. Von Laue NC, Schwappach DL, Koeck CM. The epidemiology of preventable adverse drug events: a review of literature. Wien Klin Wochenschr 2003;115 (12):407-15. 
5. Wu WK, Pantaleo N. Evaluation of outpatient drug reactions leading to hospitalization. American Journal Health System Pharmacy 2003;60(3):253-9.

6. Lazarou J, Pomeranz BH, Corey PN. Incidence of adverse drug reactions in hospitalized patients: a meta analysis of prospective studies. Journal of the American Medical Association 1998;279(15):1200-5.

7. Pirmohamed M, James S, Meakin S, et al. Adverse drug reactions as cause of admission to hospital: prospective analysis of 18,820 patients. British Medical Journal 2004;329(7456):15-9.

8. Figueiras A, Tato F, Fontainas J, et al. Influence of physicians' attitudes on reporting adverse drug events: a case control study. Medical Care 1999;37(8):809-14.

9. Cox AR, Marriott JF, Wilson KA, et al. Adverse drug reaction teaching in UK undergraduate medical and pharmacy programmes. J Clin Pharm Ther 2004; 29(1):31-5.

10. Graille V, Lapeyre-Mestre M, Montastruc JL. Drug vigilance: an opinion survey which was conducted among the residents of a university hospital. Therapie 1994; 49(5):451-4.
11. Gupta P, Udupa A. Adverse drug reaction reporting and pharmacovigilance: knowledge, attitudes and perceptions amongst resident doctors. J Pharma Sci Res 2011;3:1064-9.

12. Rehan HS, Sah SK, Chopra D. Comparison of knowledge, attitude and practices of resident doctors and nurses on adverse drug reaction monitoring and reporting in a tertiary care hospital. Indian Journal of Pharmacology 2012;44(6):699-703.

13. Deepak P, Nagaral JV. Awareness of pharmacovigilance among medical students. International Journal of Recent Trends in Science and Technology 2014;13(2):262-5.

14. Rajesh R, Vidyasagar S, Varma DM. An educational intervention to assess knowledge attitude practice of pharmacovigilance among health care professionals in an indian tertiary care teaching hospital. International Journal of Pharm Tech Research 2011;3(2):678-92. 